\title{
ELASTIC ENERGY IN INAS QUANTUM DOT-IN-A-WELL STRUCTURES
}

\author{
E. Velázquez-Lozada*, G. M. Camacho-González**, J. Quino-Cerdan*** \\ * SEPI-ESIME Instituto Politécnico Nacional (IPN), Col. Lindavista, CP 07738, México DF \\ ** ESIME-Zacatenco, IPN, Col. Lindavista, CP 07738. México DF \\ ***UNITEC - Atizapán, Blvd. Calacoaya No.7, Edo. Méx., CP 52970, México \\ Corresponding Author: Erick Velázquez Lozada, Email: evlozada5@yahoo.com.mx
}

\begin{abstract}
Keyword: Photoluminescence, Quantum dot (QD), Inhomogeneity, compressive strain
\end{abstract}
\begin{abstract}
The photoluminescence (PL), its temperature dependence and $\mathrm{X}$ ray diffraction $(\mathrm{RD})$ hav een studied in the symmetric In0.15Ga1-0.15As/GaAs quantum wells (QWs) wim vedded As quantum dots (QDs), obtained with the variation of QD growth temperaty $(4 \lambda-350 \mathrm{c})$ The increase of QD growth temperatures is accompanied by the enlargement of QD ${ }^{1}$ atera 12 up to $28 \mathrm{~nm}$ ) and by the shift non monotonically of PL peak position the $\mathrm{Ann}$, rodedure has been applied on the base of Varshni analysis to the temperature ${ }_{\text {p ndu }}$ s of $\mathrm{P}$ peaks. The obtained Varshni parameters testify that in studied QD structures process $\sigma_{\text {a }} V_{C}$ interdiffusion between QDs and capping/buffer layers takes place partially. $y$ wo this pros oss cannot explain the difference in PL peak positions.

The XRD study has revealed the high intensity $\mathrm{p} k \mathrm{ks}$ at $2 \Theta=31.6-31.80(\mathrm{~K} \alpha 1, \mathrm{~K} \alpha 2)$ that correspond to the $\mathrm{X}$ ray diffraction of the $\mathrm{K} \alpha \mathrm{l}$ and $\mathrm{K}$ lines of $\mathrm{C}$ source from the (200) crystal planes of cubic GaAs. It was shown that the XRD peak he sup position of the diffraction from the GaAs substrate and GaAs layers of quantu vells. Thu wortion of diffraction peaks related to the cubic GaAs substrate coincides with the ver wo XRD data for the bulk GaAs. It means that the elastic strain in the GaAs substrate has $b$ p elax d. At the same time the peak positions of the (200) diffraction peaks in GaAs ral laye shift to the high angles in comparison with the bulk GaAs, testifying the compr sion ain in As epitaxial layers. The minimum of elastic strain is detected in the structur w $1510 \mathrm{oC}$ that manifests itself by the higher QD PL intensity and lower the PL prakererg.

\section{INTRODUCTION}

Electronic device base on quant, wells with InAs quantum dots (QDs) have been the subject of great interest $g$ to th ari the of their applications such as: semiconductor lasers for the optical fiber communicat 1-3], in ared photo-detectors [4-6] and electronic memory devices [7,8]. For laser or $n^{2}$ liode lic cons the surface density of QDs has to be high [9-14]. It was shown earlier 3] the the InA, QD density can be increased essentially if the QDs are grown inside of GaAs/a in optimal Q rowth parameters and the capping/buffer layer compositions, the InAs QD structures are characte $\mathbb{A}$ by photoluminescence (PL) inhomogeneity along the wafers [15-18]. The technology of growth of InAs QD structures has become more reliable enabling systematic studies their physical properties. In this paper we try to understand the physical reasons of emission inhomogeneity of InAs QDs coupled with symmetric In0.15Ga0.85As/GaAs quantum wells (QWs) at the variation of the density and the size of InAs QDs grown at different temperatures.
\end{abstract}

\section{EXPERIMENTAL CONDITIONS}

A set of samples was prepared using molecular beam epitaxy on (100) oriented $2^{\text {ecee }}$ diameter semi-insulating GaAs substrates (Fig.1). InAs quantum dots (QDs) were grown inside of the symmetric In $0.15 \mathrm{Ga} 0.85 \mathrm{As} / \mathrm{GaAs}$ quantum wells (the same In concentrations in buffer and capping 
In0.15Ga0.85As layers) at five QD growth temperatures $470(\# 1), 490(\# 2), 510(\# 3) 525$ (\#4) and 535 (\#5)oC during the deposition of InAs active regions and InGaAs wells [12,14]. The QD size increases from 12 to $28 \mathrm{~nm}$ and the QD density decreases from 1.11011 down to $1.31010 \mathrm{~cm}-2$ versus QD growth temperatures [19]. Photoluminescence spectra were measured in the temperature range of 10-300 $\mathrm{K}$ using the excitation by the $536 \mathrm{~nm}$ line of a solid state laser model V-5 COHERENT Verdi at an excitation power density from the range of $300 \mathrm{~W} / \mathrm{cm} 2$. PL spectra were dispersed by a SPEX $500 \mathrm{M}$ spectrometer with a Ge detector. The X-ray diffraction (XRD) experiments were made using the XRD equipment model of D-8 advanced (Bruker Co) with K $\alpha 1$ line from the $\mathrm{Cu}$ source $(\lambda=1.5406 \mathrm{~A})$.

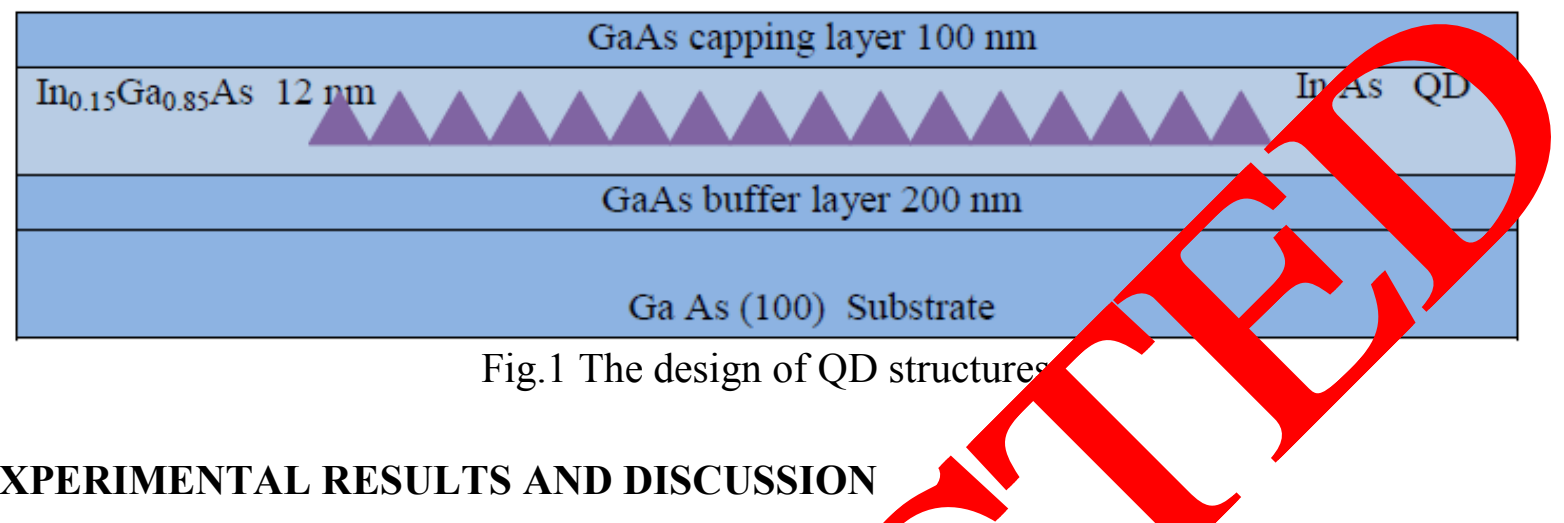

\section{EXPERIMENTAL RESULTS AND DISCUSSION}

I Typical PL spectra of the structure \#3 measured at $d$ fferent temperaty es at the excitation light density of $300 \mathrm{~W} / \mathrm{cm} 2$ are shown in Fig.2.

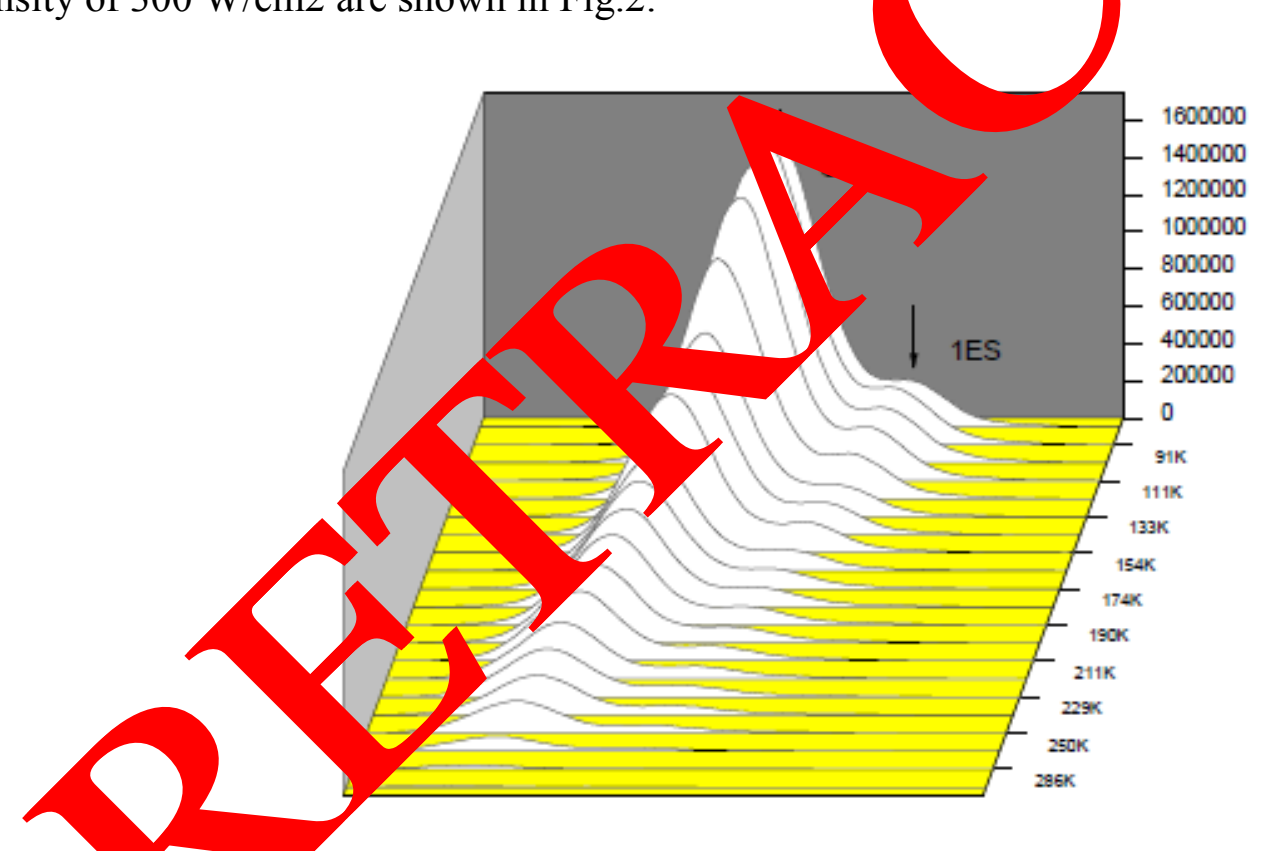

Fig. 2. 1. Cal PL spectra measured at different temperatures for the DWELL structure \#3 at the excitation density of $300 \mathrm{~W} / \mathrm{cm} 2$.

Two PL bands appear due to the recombination of excitons localized at a ground state (GS) and at an excited state (1ES) in QDs (Fig.2). The excitations light density of $300 \mathrm{~W} / \mathrm{cm} 2$ is chosen for prevent the influence of ES emission on the GS PL intensity (Fig.2). The QD diameters in studied structures increase monotonically from 12 up to $28 \mathrm{~nm}$ with the rise of QD growth temperatures from 470 up to $535 \mathrm{oC}$. Thus it is possible to expect that the PL peak position in QDs has to shift monotonically to low energy. Fig.3 presents the PL peak positions in the structures (\#1- \#5) measured at 10-160 K for GS PL bands. As it is clear the variation of PL peak positions with enlargement of QD growth temperatures and QD diameters is none monotonical. 


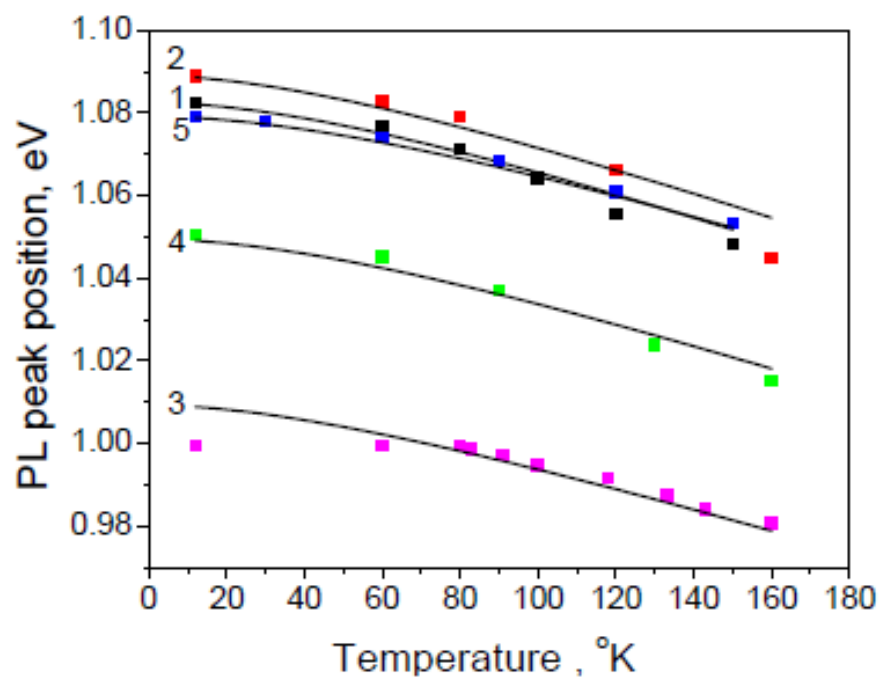

Fig. 3. The variation of PL peak positions versus temperatures. The lines $p$ esent the $V \hat{a}_{\text {ni }}$ itting results: 1- \#1, 2- \#2, 3- \#3, 4-\#4 and 5 - \#5

Note that lower PL peak energy corresponds to higher PL int ASiny ( 1 ). Tw reasons can explain the variation non monotonically of PL peak positions 3 PL into in studied QD structures: (i) the change of QD composition due to the $\mathrm{Ga} / \mathrm{In}$ er $\mathrm{d}$ ion bety een InAs QDs and capping/buffer In0.15 Ga0.85As QW layers or (ii) the rent le elastic strain in QD structures due to the difference in QD densities and s zes. To distingu $n$ these two reasons PL spectra at different temperatures in the range 10-160 K ave been studied. The variation of PL peak positions of ground state PL bands in all studied QD st tures is presented in Fig. 3. PL peaks shift to low energy with increasing temperature due to the present the fitting results analyzed on the ba Varshntrelation that presents the energy gap variation with temperature as [20]:

The comparison of fitting ra, in the bulk InAs crystal (T Ge 1) has ealed that in studied QD structures the fitting parameter "a" and „be in the temr cra range $10,60 \mathrm{~K}$ are very close to their values for the bulk InAs crystal (Table 1) in the PD st ure \#3. But in other QD structures the fitting parameter "a" and

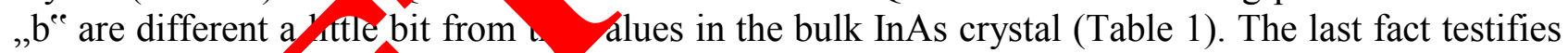
that the process $\mathrm{Ga} / \mathrm{I}$ inter diffusion takes place in these QD structures. Note that the process of $\mathrm{Ga} / \mathrm{In}$ inter din in $\mathrm{s}$ died structures passes non monotonically versus QD growth temperatur It mea that $\mathrm{n}$ ot only temperature but some other factors are essential as well.

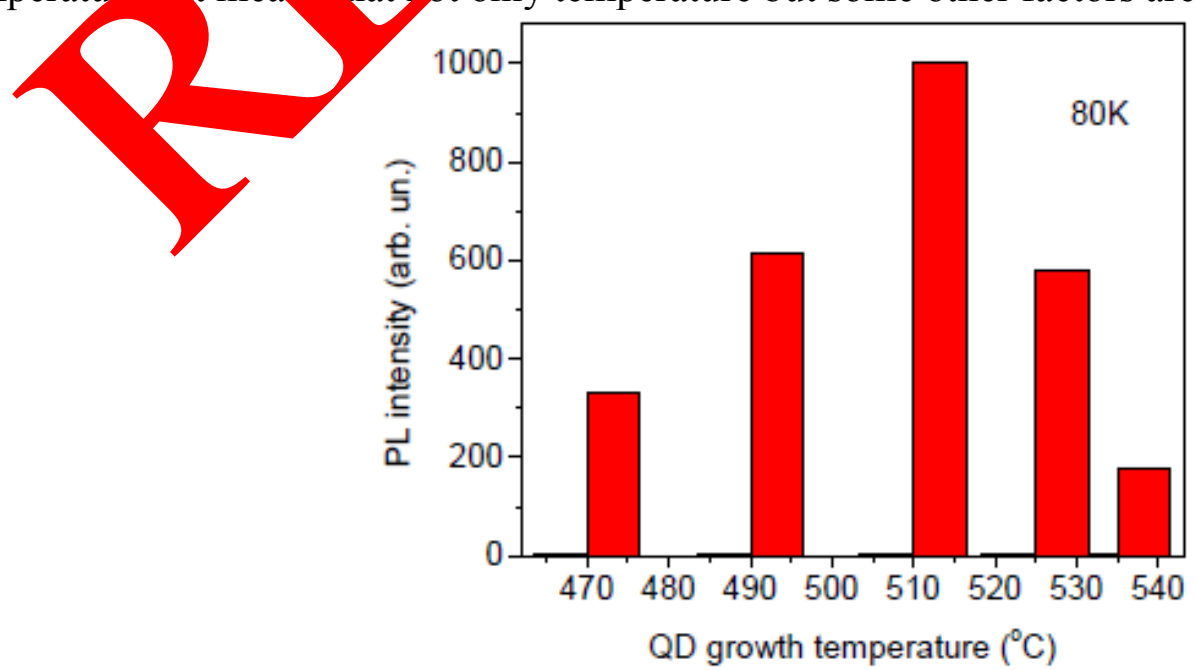

Fig. 4. Histogram of average PL peak intensities in studied structures 
Figures 5 presents the superposition of XRD peaks related to the diffraction of $K_{\alpha 1}$ and $K_{\alpha 2}$ lines of the X-ray $\mathrm{Cu}$ source from the (200) crystal planes of cubic GaAs substrate and GaAs layers in studied $\mathrm{In}_{0.15} \mathrm{Ga}_{0.85} \mathrm{As} / \mathrm{GaAs}$ QWs. As one can see in figure 5 the peaks $\left(31.69-31.70^{\circ}\right.$ and 31.77 $31.78^{\circ}$ ) related to the diffraction of $\mathrm{K}_{\alpha 1}$ and $\mathrm{K}_{\alpha 2}$ lines from the (200) crystal planes in GaAs QW layers with QDs grown at $490-525{ }^{\circ} \mathrm{C}$ locate more close to the corresponding XRD peaks $\left(31.63^{\circ}\right.$ and $31.71^{\circ}[22]$ ) of the bulk cubic GaAs (Fig.5).

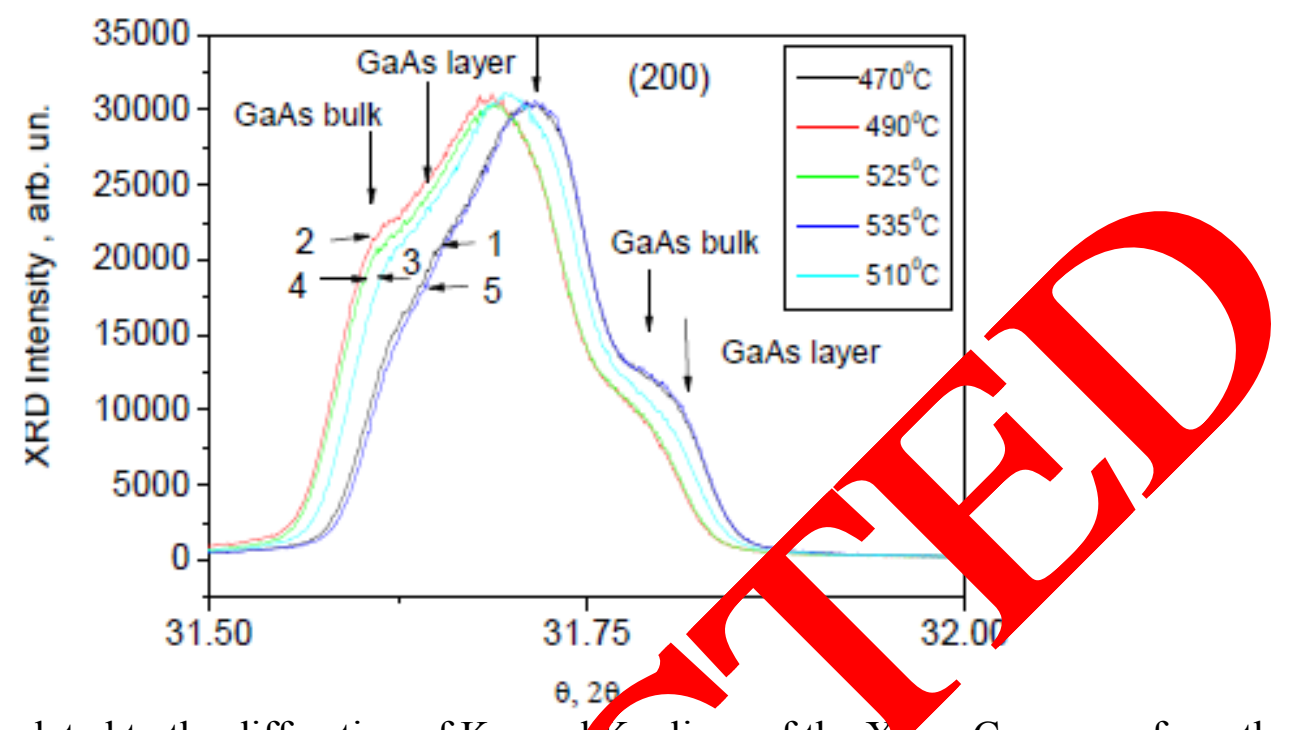

Fig. 5. XRD peaks related to the diffraction of $K_{\alpha 1}$ and $K_{\alpha 2}$ lines of the $X$ ray $\mathrm{Cu}$ source from the (200) crystal planes of the GaAs substrate and GaAs $\mathrm{C}$ layers in s'udied structures: 1- \#1, 2- \#2, 3- \#3, 4-\#4 and

\section{CONCLUSION}

The last fact indicates that the level of elasti ain $1 / \operatorname{In}_{0.15} \mathrm{Ga}_{0.85} \mathrm{As} / \mathrm{GaAs} \mathrm{QWs}$ of \#2, \#3, \#4 is smaller than in the structures \#1 a In QD ructures with QDs grown at 470 and $535{ }^{\circ} \mathrm{C}$ the corresponding XRD peaks shift $t$ highe angles $\left(1.72^{\circ}\right.$ for $\mathrm{K}_{\alpha 1}$ and $31.80^{\circ}$ for $\mathrm{K}_{\alpha 2}$ ) testifying the higher levels of compressive tra ir s of structures \#1 and \#5 (Fig.5). The lowest integrated PL intensities ha e been do ted in the QD structures \#1 and \#5, apparently, due to the high concentration of 0 liative ( $/$ defects. The high level of elastic strain enhances, apparently, partial stre rela ion in the QD structures \#1 and \#5 that accompanies by the appearance of NR $\mathrm{ctects}$.

\section{REFERENCES}

[1]. D. Pilm g, M. ınam, N. N. Ledentsov, Quantum Dot Heterostructures, Ed. Wiley \& Sons 01$) 38$.

[2] D. L Jrundmann, F. Heinrichsdorff, N.N. Ledentsov V.M. Ustinov, A.E. Zhukov, A.R. Kovs M.V. Maximov, Y.M. Shernyakov, B.V. Volovik, A.F. Tsatsul'nikov, P.S. Kop'ev, Zh.I. Alferov, Ain Solid Films 367, 235 (2000).

[3]. G. T. Liu, A. Stintz, H. Li, K. J. Malloy and L. F. Lester, Electron Lett. 35, 1163 (1999).

[4] A. Amtout, S. Raghavan, P. Rotella, G. von Winckel, A. Stinz, S. Krishna, J. Appl. Phys. 96, 3782 (2004).

[5] R.S. Attaluri, J. Shao, K.T. Posani, S.J. Lee, J.S. Brown, A. Stintz, S. Krishna, J. Vac. Sci. Technol. B 25, 1186 (2007).

[6] T.V. Torchinskaya, Opto-Electronics Review 6 (2), 121 (1998).

[7] D. Haft, R. J. Warburton, K. Karrai, S. Huant, G. Medeiros-Ribeiro, J. M. Garsia, W. Schoenfeld, P. M. Petroff, Appl. Phys. Lett. 78, 2946 (2001).

[8] M. Geller, A. Marent, T. Nowozin, D. Feise, K. Potschke, N. Akcay, N. Oncana, D. Bimberg, Physica E 40, 1811 (2008). 
[9] I. Kamiya, I. Tanaka, K. Tanaka, F. Yamada, Y. Shinozuka, and H. Sakaki: Physica E 13, 131 (2002).

[10] K. Karrai, R. J. Warburton, C. Schulhauser, A. Hogele, B. Urbaszek, E. J. McGhee, A. O. Govorov, J. M. Garcia, B. D. Gerardot, and P. M. Petroff: Nature 427, 135 (2004).

[11] R. M. Thompson, R. M. Stevenson, A. J. Shields, I. Farrer, C. J. Lovo, D. A. Ritchie, M. L. Leadbeater, and M. Pepper: Phys. Rev. B 64, 201302 (2001).

[12] A. Stintz, G. T. Liu, L. Gray, R. Spillers, S. M. Delgado, K. J. Malloy, J. Vac. Sci. Tech. B 18 (3), $1496(2000)$.

[13] S.P. Ryu, N.K. Cho, J.Y. Lim, H.J. Lee, W.J. Choi, J.D. Song, J.I. Lee and Y.T. Lee Japan. J. Appl. Phys. 48, 095506 (2009).

[14] T. V. Torchynska, J. Appl. Phys. 104 (7), 074315 (2008).
[15] T. V. Torchynska, J. L. Casas Espinola, L. V. Borkovska, S. Ostapenko, M. Dy ic, O. pan, N. O. Korsunska, A. Stintz, P. G. Eliseev, K. J. Malloy, J. Appl. Phys. 101, 02432 2007).

[16] M. Dybiec, S. Ostapenko, T. V. Torchynska, E.Velazquez Lozada, Appl. Phys. + 84, 5 ,5 (2004).

[17] M. Dybiec, S. Ostapenko, T. V. Torchynska, E.Velazquez Lozada, P G. Elis y, A. ntz, K. J. Malloy, Phys. Stat. Sol. (c) 2, 2951 (2005).

[18] M. Dybiec, L. Borkovska, S. Ostapenko, T. V. Torchynska, J . Casas L

K. J. Malloy, Applied Surface Science 252, 5542 (2006).

[19] T.V. Torchynska, A. Stintz, J. Applied Physics 108, 2, 02. 16 (2

[20] Y. P. Varshni, Physica 34, 149 (1967).

[21] A. Landolt-Boernstein, Numerical Data and Functi hal Relationship, n: Science and Technology, 22 (Springer, Berlin, (1987) p. 118.

[22] C.Y. Yeh, Z.W. Lu, S. Froyen and A. Zunger, Phys ev. B 46,10086 (1992).

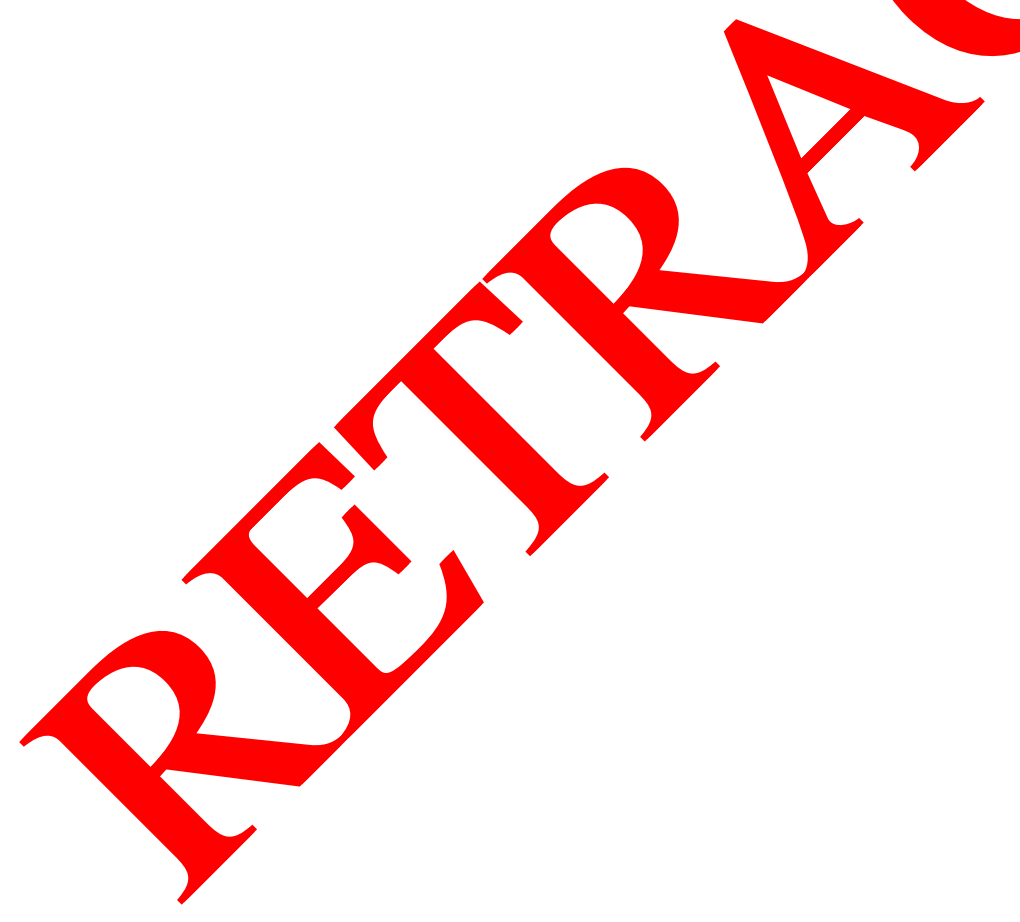

